\title{
Nectar composition in moth-pollinated Platanthera bifolia and $P$. chlorantha and its importance for reproductive success
}

\author{
Emilia Brzosko · Andrzej Bajguz ${ }^{1}$ (1) \\ Received: 19 January 2019 / Accepted: 12 April 2019 / Published online: 17 April 2019 \\ (c) The Author(s) 2019
}

\begin{abstract}
Main conclusion Sugars (glucose, fructose and sucrose), as well as proteogenic and non-proteogenic amino acids, are present in the nectar of Platanthera bifolia and $P$. chlorantha.
\end{abstract}

\begin{abstract}
Nectar quantity and quality are floral traits that are subjected to pollinator-mediated selection. Nectar sugar and amino acid (AA) composition in two sister species, P. bifolia and $P$. chlorantha, was analysed and the interspecies differences in nectar and the importance of these nectar characteristics for reproductive success were investigated. Nectar was collected from four $P$. bifolia and three $P$. chlorantha populations that exist in different habitats in three regions of NE Poland. Nectar from about 30 flowers (from each population) was sampled and analysed using high-performance liquid chromatography. We found the same primary sugars and AA components in the nectar of both species, although their content varied between the populations according to habitat properties. The nectar of $P$. bifolia and $P$. chlorantha both had low sugar concentrations (9.04-20.68\%) and were dominated by hexoses, with sucrose:hexoses ratios between 0.03 and 0.31 across the different populations (the average for the $P$. bifolia populations was 0.17 and the average for the $P$. chlorantha populations was -0.05). Total sugar content did not influence reproductive success and we found positive selection on fructose content. In general, 23 different AAs were detected in both Platanthera species. Cysteine and $\gamma$-aminobutyric acid were present in only one population of $P$. chlorantha. Sarcosine dominated among the non-proteogenic AAs. To our knowledge, this is the first report that characterizes the sugar and AA profiles in the nectar of $P$. bifolia and $P$. chlorantha in natural populations in the context of effectiveness of reproduction. Total AAs negatively influenced male reproductive success $(r=-0.79)$. Pollinators of the investigated species were found to be sensitive to the AAs' taste, from taste classes I and IV. Correlation between male reproductive success and the content of AAs from these groups was 0.79 in both cases. In this manuscript, we investigated the characteristics of $P$. bifolia and $P$. chlorantha nectar, and compared these characteristics to the available data in the context of their adaptations to the requirements of pollinators and with regard to the importance of nectar quality for reproductive success of the studied species.
\end{abstract}

Keywords Amino acids $\cdot$ NE Poland $\cdot$ Sugars $\cdot$ Pollination success

Electronic supplementary material The online version of this article (https://doi.org/10.1007/s00425-019-03168-5) contains supplementary material, which is available to authorized users.

Andrzej Bajguz

abajguz@uwb.edu.pl

1 Faculty of Biology and Chemistry, Institute of Biology, University of Bialystok, Konstantego Ciolkowskiego 1J, 15-245 Białystok, Poland

\section{Introduction}

The wide varieties of flower types that have evolved in plants are adapted in different ways to their pollinators. The structure of the flower and other traits that include colour or scent are often subjected to pollinator-mediated selection (Maad 2000; Leiss and Klinkhamer 2005; Nepi et al. 2018; Parachnowitsch et al. 2019). One of these traits being the evolutionary answer for pollinators' preferences is nectar. Many studies document that nectar concentration and composition are often linked with pollinator types (Baker and Baker 1983; Nicolson and Thornburg 2007; Petanidou 2007; Witt 
et al. 2013; Fowler et al. 2016; Tiedge and Lohaus 2017). Pollinators have different requirements with respect to nectar content, both for sugar and amino acid (AA) concentrations, composition and other nectar components such as nectarins, vitamins, phenolics, alkaloids, terpenoids, lipids, metal ions and phytohormones (Baker and Baker 1983; Adler 2000; Petanidou 2007; Gijbels et al. 2014, 2015a, b; Roy et al. 2017; Tiedge and Lohaus 2017).

Most studies report three main sugar components in nectar: sucrose, glucose and fructose, which occur in different proportions, although sucrose is most often considered to be the dominant ingredient (Nicolson and Thornburg 2007; Fowler et al. 2016; Parachnowitsch et al. 2019). Nevertheless, plants that produce nectar that is dominated by hexoses are not so rare (Nocentini et al. 2013). Other carbohydrates, e.g. mannose, xylose and maltose are present in floral nectars less frequently (Nicolson and Thornburg 2007). Some authors suggest that the sugar ratio [sucrose/(glucose + fructose)] is linked to the different types of pollinators (Baker and Baker 1990; Nicolson and Thornburg 2007; Witt et al. 2013). The preferences of pollinators are partially caused by the adaptation of their mouthparts to use nectar with a given level of sugar concentration that is dependent on different viscosities and flux. Heyneman (1983), on the basis of data reported by Pyke and Waser (1981) and Baker and Baker (1982), reported that the highest concentration of sugars in nectar is characteristic of bee-pollinated flowers (on average 35\%), while the lowest is typical for those pollinated by bats (17\%) or hawk moths (19\%). Further studies have expanded this information and verified the concept. For example, Willmer (2011) documented that the optimal feeding rates of lepidopteran occur with higher sugar concentrations (35-45\%) than earlier authors reported. Simultaneously, Willmer (2011) noted that nectar with a sugar concentration above $30-40 \%$ is difficult to suck up for most lepidopterans because of their long tongues, which require dilute nonviscous nectar. Pollinators' preferences also result from the energetic costs connected with their behaviour. For example, hawk moths feed primarily while hovering and mainly at night (at lower temperatures); thus, this type of activity requires more energy (Willmer 2011; Fowler et al. 2016).

The next group of nectar components that play an important role in plant-pollinator interactions is AAs (Nicolson and Thornburg 2007; Roy et al. 2017; Nepi et al. 2018). Despite their concentrations being much lower than sugars, AAs are the basic source of nitrogen for animals that feed on nectar and different AAs may cause different gustatory and stimulatory effects (Gardener and Gillman 2002; Zhang et al. 2006; Fowler et al. 2016). Some studies document that insects feeding on nectars that are rich in AAs are larger, have greater longevity and produce more offspring with higher fitness (Mevi-Schütz and Erhardt 2005; Fowler et al. 2016). Available studies have also documented the differentiated composition of AAs in nectar from different taxonomic and ecological plant groups and determined the preferences of pollinators for specific AAs (Willmer 2011; Nocentini et al. 2013; Antoń et al. 2017; Tiedge and Lohaus 2017).

Many studies have reported the presence of other compounds in nectar. These include non-proteogenic AAs and secondary metabolites, such as alkaloids, phenolics, iridoid glycosides, and glucosinolates cardenolides, which have varying functions (Baker 1977; Adler 2000; Nicolson and Thornburg 2007; Vranová et al. 2010; Roy et al. 2017; Nepi et al. 2018; Parachnowitsch et al. 2019). The majority of the published data suggest that these compounds generally reduce pollinator preferences and simultaneously decrease reproductive success (Adler 2000; Parachnowitsch et al. 2019). For example, experimental studies conducted by Adler and Irwin $(2005,2012)$ revealed that with higher levels of gelsemine in nectar from Gelsemium sempenvirens, parameters that quantify reproductive success are decreased. On the other hand, Kessler et al. (2008) found that nicotine in Nicotiana attenuata reduces nectar robbing, florivory and nectar consumption, which results in increased reproductive success. Some studies document that pollinators' responses to secondary metabolites can be concentration dependent. At higher concentrations, visitors are most often deterred, while at lower concentrations, nectar may be attractive. This effect translates into higher levels of reproduction (Singaravelan et al. 2005; Manson et al. 2013; Thomson et al. 2015; Baracchi et al. 2017). Moreover, some secondary metabolites (e.g. gelsemine, anabasine or nicotine) may benefit pollinators by increasing their resistance to herbivores, parasites and pathogens (Stevenson et al. 2017; Nepi et al. 2018).

It should be noted that the quantity and quality of nectar depend on pollinators' preferences and also on other biotic and abiotic factors that include the presence of microbes, availability of soil resources, water availability, sun exposure and/or weather conditions (Gardener and Gillman 2001; Nicolson and Thornburg 2007; Farkas et al. 2012; Nocentini et al. 2013; Gijbels et al. 2014, 2015a, b; Nepi et al. 2018; Parachnowitsch et al. 2019).

Because nectar composition is often subjected to strong pollinator-mediated selection (Leiss and Klinkhamer 2005; Gijbels et al. 2015a, b) its quantity and quality greatly affect the reproductive success of nectariferous plants (Tremblay et al. 2005; Duffy and Stout 2011; Willmer 2011; Gijbels et al. 2014, 2015a, b; Pyke 2016). Generally, the majority of the previous studies have reported that greater nectar volume increases pollinators' visitation rate and in effect, increases their reproductive success (Neiland and Wilcock 1998; Tremblay et al. 2005; Nepi et al. 2018), although others have noted results that contrast with this finding or found only a weak (or no) relationship between nectar characteristics and 
the level of reproduction (Ackerman et al. 1994; Duffy and Stout 2011). Nectar may not simply function as a reward, increasing visitation rates and furthering reproduction levels, but may also be a 'manipulator' of pollinator behaviour, which can also be an important factor shaping reproductive success (Pyke 2016). Despite the undeniable importance of nectar quantity and quality for reproductive success, its presence can have negative effects. It can promote self-pollination and in consequence, increase inbreeding depression, thus reducing the fitness of progeny (Jersáková and Johnson 2006).

Many representatives of the Orchidaceae attract pollinators by offering different rewards, e.g. resins, oil, fragrance or pseudopollen, out of which nectar is most effective (Neiland and Wilcock 1998; Tremblay et al. 2005). Nevertheless, although problems concerning pollinator-mediated selection on floral traits in this group are among the most important and are often examined, there are surprisingly few data regarding the composition of nectar in orchids, especially in comparison to the large number of species that belong to this family. Only a few studies can be found on this topic in orchids, and these are mainly in a restricted range in their reporting of nectar composition (Stpiczyńska and Pielecki 2002; Stpiczyńska 2003a, b; Martins and Johnson 2007; Gijbels et al. 2014, 2015a, b). Some of the most detailed studies were conducted by Stpiczyńska (2001, 2003a) and Stpiczyńska and Pielecki (2002) on P. chlorantha. They report the nectar secretion, chemistry and its dynamics during the flowers' life under laboratory conditions. The recent studies by Lindqvist et al. (2018), which tested a novel technique, are methodical in their character and analysed sugars from only 18 flowers of the two Platanthera species. Both species were intensively investigated in the context of pollination biology, spatial variation of reproductive success (focusing on pollinator-mediated selection of floral traits), hybridization and genetic diversity (Nilsson 1983, 1985; Brzosko 2003; Maad and Alexandersson 2004; Maad and Nilsson 2004; Bateman and Sexton 2008; Brzosko et al. 2009; Bateman et al. 2012; Claessens and Kleynen 2011; Steen 2012; Steen and Mundal 2013; Brzosko and Wróblewska 2013; Boberg et al. 2014; Sexton 2014; Esposito et al. 2017; Durka et al. 2017; Duffy and Stout 2011; Esposito et al. 2018; Mõtlep et al. 2018). Our interest stems from the fact that this species pair is a suitable model system to study co-evolutionary processes. The main differences between the two Platanthera species are column structure and connected with this structure's pollinaria attachment (tongue attachment in P. bifolia and eye attachment in $P$. chlorantha) as well as the ethological mechanism, resulting from the differential attraction of pollinators due to differences in floral scent chemistry (Nilsson 1983, 1985; Esposito et al. 2017). These differences result in moths that belong to the noctuids being better adapted to pollinate $P$. chlorantha, while sphingids are the main pollinators of $P$. bifolia, although both Platanthera species may share the main pollinators (Nilsson 1983).

In the context of the above-mentioned problems, it is interesting to examine whether nectar composition is the next trait that differentiates these two sister species. Therefore, the main aims of these experiments were to determine answers for the following questions: (1) What is the composition of nectar produced by $P$. bifolia and $P$. chlorantha? (2) Is nectar chemistry species or habitat dependent? (3) Is reproductive success in populations of both species influenced by nectar content and composition?

\section{Materials and methods}

\section{Studied species and localization}

The 'Butterfly Orchids' Platanthera bifolia L. (Rich.) and $P$. chlorantha (Cust.) Rchb. are a closely related and widely distributed species, which largely occur in sympatry (Hultén and Fries 1986). Both species have overlapping flowering times. The inflorescences of both species develop 10-25 white flowers with a long spur containing nectar. The spur length is differentiated within a geographic range, which is connected with the proboscis length of local pollinators (Nilsson 1985; Maad and Nilsson 2004; Bateman and Sexton 2008; Boberg and Ägren 2009; Claessens and Kleynen 2011). According to Bateman and Sexton (2008), $P$. chlorantha usually possesses longer spurs than $P$. bifolia, although both short- and long-spurred populations of these two species have been reported (Boberg et al. 2014). The two Platanthera species differ significantly in flower morphology. In P. bifolia, the pollinaria have very short caudicles that are positioned almost parallel to each other, and the distance between viscidia is much smaller than in $P$. chlorantha. Moreover, the column in $P$. bifolia is small with a narrow connective and in $P$. chlorantha the column is wide with a broad connective (Maad and Nilsson 2004). These differences result in the pollinaria of $P$. bifolia being attached to the moths' proboscis, while in $P$. chlorantha they are attached to the eyes. In effect, $P$. bifolia is predominantly adapted to pollination by hawk moths (Sphingidae) and $P$. chlorantha by noctuids (Noctuidae) (Nilsson 1983). The two Platanthera species also differ according to their floral scent chemistry; thus, they attract pollinators in different ways, which is an ethological mechanism of reproductive isolation that reduces hybridization (Nilsson 1983, 1985; Esposito et al. 2018).

This study was performed during 2017 at three locations in NE Poland and included four P. bifolia (SMOL, POG, POB1 and BC) and three $P$. chlorantha (BON, LIN, $\mathrm{BF})$ populations. Populations were localized in Białowieża 
National Park (two populations), Biebrza National Park (1 population) and Suwałki Landscape Park (four populations) (Table 1). These populations existed in different plant communities: two populations (one of each species, LIN and $\mathrm{BC}$ ) in multispecies meadows and the remaining in forests or under tree canopy (Table 1).

\section{Reproductive success}

To evaluate the reproductive success (RS) in P. bifolia and $P$. chlorantha populations, during the peak of flowering, we marked the inflorescences and counted the number of flowers. During late July, female and male reproductive success was quantified. Female reproductive success (FRS) was evaluated (as a percentage) as the proportion of fruits developed to the sum of flowers on the inflorescence. Male reproductive success (MRS) was determined as the percent of pollinaria removal for each plant to the total number of pollinaria present on the inflorescence. The number of plants for which reproductive success was determined is shown in Table 1.

\section{Chemicals}

Standards of AAs: L-aspartic acid (Asp), L-glutamic acid (Glu), L-arginine (Arg), L-histidine (His), L-lysine (Lys), glycine (Gly), L-alanine (Ala), L-isoleucine (Ile), L-leucine (Leu), L-methionine (Met), L-phenylalanine (Phe), L-proline (Pro), L-tryptophan (Trp) L-valine (Val), L-citrulline (Cit), L-hydroxyproline (Hyp), L-norvaline (Nva), L-ornithine
(Orn), sarcosine (Sar), taurine (Tau), $\alpha$-aminobutyric acid (AABA), $\beta$-alanine ( $\beta$-Ala), $\beta$-aminobutyric acid (BABA), $\gamma$-aminobutyric acid (GABA), L-asparagine (Asn), L-cysteine (Cys), L-glutamine (Gln), L-serine (Ser), L-threonine (Thr), L-tyrosine (Tyr) were purchased from Sigma-Aldrich (St. Louis, MO, USA) in ACS purity. Other chemicals: $o$-phthalaldehyde (OPA) and 9-fluorenylmethyl chloroformate (FMOC) reagents, borate buffer $(0.4 \mathrm{~N}$ in water, $\mathrm{pH} 10.2)$, $\mathrm{NaH}_{2} \mathrm{PO}_{4}$ and $\mathrm{NaOH}$, were also purchased from SigmaAldrich (St. Louis, MO, USA). Acetonitrile (ACN), methanol $(\mathrm{MeOH})$ and water were purchased from Merck KGaA (Darmstadt, Germany) in LC-MS grade.

\section{Determination of amino acids and sugars in nectar}

The nectar standing crop (nectar column) was measured in the field to the nearest $0.01 \mathrm{~mm}$ using an electronic calliper. For all populations, the nectar column was recorded in the same phase of inflorescence development in flowers open to flower visitors. During measurements, the vast majority of them did not have any marks of visitation (pollinaria were present and massules on the column were absent). The measurements were done for the lowest flower on the inflorescence (the first flower from the bottom) for all plants that reproductive success was evaluated. To analyse nectar composition in each of seven populations, nectar from about 30 of the lowest flowers on the inflorescence was sampled. A single analytical sample was nectar from about 30 flowers from about 30 individuals in each population. Nectar from the flowers of each population was placed in a $200-\mu \mathrm{L}$

Table 1 Characteristics of Platanthera bifolia i P. chlorantha populations

\begin{tabular}{|c|c|c|c|c|c|c|}
\hline Region of NE Poland & Population code & Type of habitat and community & $\begin{array}{l}\text { Number of indi- } \\
\text { viduals analysed } \\
\text { for RS }\end{array}$ & FRS $(\%)$ & $\operatorname{MRS}(\%)$ & $\begin{array}{l}\text { Nectar column } \\
\text { length }(\mathrm{mm}) \pm \mathrm{SE}\end{array}$ \\
\hline \multicolumn{7}{|l|}{ Suwałki Landscape Park } \\
\hline & SMOL & $\begin{array}{l}\text { The remnant forest fragment with } \\
\text { domination of Betula pendula and } \\
\text { Picea abies in tree canopy and } \\
\text { poor undergrowth layer }\end{array}$ & 90 & 73.7 & 80.1 & $8.69 \pm 4.50$ \\
\hline & POB1 & $\begin{array}{l}\text { Dense, young, artificial spruce forest } \\
\text { with small gaps dominated by } \\
\text { grasses }\end{array}$ & 62 & 26.6 & 56.9 & $7.61 \pm 3.53$ \\
\hline & LIN & $\begin{array}{l}\text { Multispecies meadow surrounded by } \\
\text { open areas }\end{array}$ & 96 & 57.0 & 95.2 & $7.87 \pm 3.04$ \\
\hline & BON & Broadleaved forests & 36 & 52.5 & 78.9 & $9.80 \pm 5.55$ \\
\hline \multicolumn{7}{|l|}{ Biebrza National Park } \\
\hline & POG & $\begin{array}{l}\text { The border of alder forest and peat } \\
\text { bogs, mainly in open area }\end{array}$ & 46 & 60.2 & 85.9 & $15.94 \pm 5.05$ \\
\hline \multicolumn{7}{|c|}{ Białowieża National Park } \\
\hline & $\mathrm{BC}$ & $\begin{array}{l}\text { Multispecies meadow surrounded } \\
\text { by forests }\end{array}$ & 78 & 17.8 & 86.8 & $5.80 \pm 5.42$ \\
\hline & $\mathrm{BF}$ & Broadleaved forests & 72 & 73.9 & 87.3 & $4.49 \pm 3.10$ \\
\hline
\end{tabular}


Eppendorf tube prior to analysis using high-performance liquid chromatography (HPLC). The samples were frozen $\left(-20{ }^{\circ} \mathrm{C}\right)$ until required. Nectar was diluted with water to a volume of $50 \mu \mathrm{L}(10 \mu \mathrm{L}$ of nectar and $40 \mu \mathrm{L}$ of distilled water) for sugar analysis and of $20 \mu \mathrm{L}(10 \mu \mathrm{L}$ of nectar and $10 \mu \mathrm{L}$ of distilled water) for AA analysis. The sample was filtered through a spin column with a $0.4-\mu \mathrm{m}$-pore size membrane filter (A\&A Biotechnology, Poland) by centrifugation for $2 \mathrm{~min}$ at $9000 \mathrm{~g}$ (relative centrifugal force) before injection. The supernatant was loaded into the insert and analysed by HPLC. Analyses were performed using an Agilent Technologies 1260 Infinity series system consisting of a 1260 Infinity Agilent Quaternary pump G1311B, a 1260 Infinity Diode Array Detector (DAD) G1315D, a 1260 Infinity Fluorescence Detector (FLD) G1321B, a 1260 Infinity ALS G1329B Automated Sample Injector, a 1290 Infinity Autosampler Thermostat G1330B, and a thermostatted column oven 1290 Infinity TCC G1316C. The system was controlled by Agilent OpenLab ChemStation software.

A ZORBAX Carbohydrate Analysis Column $(4.6 \mathrm{~mm} \times 250 \mathrm{~mm}, 5 \mu \mathrm{m})$ was used for sugar separation and analysis. A $10 \mu \mathrm{L}$ aliquot sample or standard solution was injected. The separation was conducted at $30{ }^{\circ} \mathrm{C}$ with the mobile phase comprising ACN:water (70:30, v/v) at a flow rate of $1.4 \mathrm{~mL} \mathrm{~min}^{-1}$. The analytical data were integrated using the Agilent OpenLab CDS ChemStation software for liquid chromatography systems. Identification of sugars was performed by comparing retention times of individual sugars in the reference vs. test solution. The content of glucose, fructose, sucrose, maltose, and lactose was assayed based on comparisons of peak areas obtained for the samples investigated with those of the reference solutions.

Amino acid analysis was performed with gradient HPLC using an Agilent Zorbax Eclipse Plus $\mathrm{C}_{18}(4.6 \times 150 \mathrm{~mm}$, $5 \mu \mathrm{m})$ column with a guard, i.e. Agilent Zorbax Eclipse Plus $\mathrm{C}_{18}(4.6 \times 12.5 \mathrm{~mm}, 5 \mu \mathrm{m})$. The extracts containing primary and secondary AAs were pre-column derivatized using an OPA and FMOC reagent. An injector program was used for derivatization. After the derivatization step, a mixture of each sample was injected into a pre-equilibrated column operated at $40{ }^{\circ} \mathrm{C}$. The primary AAs (OPA-derivatized) were monitored at $388 \mathrm{~nm}$ by DAD and the secondary AAs (FMOC-derivatized) were monitored by FLD at an excitation wavelength of $266 \mathrm{~nm}$ and an emission wavelength of $305 \mathrm{~nm}$. Mobile phase A was $40 \mathrm{mM} \mathrm{NaH} \mathrm{PO}_{4}(\mathrm{pH} 7.8$ adjusted using $10 \mathrm{M} \mathrm{NaOH}$ solution), while mobile phase $\mathrm{B}$ was $\mathrm{ACN}: \mathrm{MeOH}$ :water (45:45:10, v/v/v). Gradient profile was the following: $0-5 \mathrm{~min}, 0 \% \mathrm{~B}$ to $10 \% \mathrm{~B} ; 5-25 \mathrm{~min}, 10 \%$ $\mathrm{B}$ to $40.5 \% \mathrm{~B} ; 25-30 \mathrm{~min}, 40.5 \% \mathrm{~B}$ to $63 \% \mathrm{~B} ; 30-35 \mathrm{~min}$, $63 \% \mathrm{~B}$ to $82 \% \mathrm{~B} ; 35-37 \mathrm{~min}, 82 \% \mathrm{~B}$ to $100 \mathrm{~B} ; 37-39 \mathrm{~min}$, $100 \% \mathrm{~B} ; 39-40 \mathrm{~min}, 100 \% \mathrm{~B}$ to $0 \% \mathrm{~B} ; 40-43 \mathrm{~min}, 0 \% \mathrm{~B}$. A flow rate of $1 \mathrm{~mL} \mathrm{~min}^{-1}$ was used. The total analysis time was $43 \mathrm{~min}$.

\section{Statistics}

All statistical analyses were performed using R software ( R Core Team 2018). Nectar column length in spurs, FRS and MRS for each population of $P$. bifolia and P. chlorantha were further assessed for normality and homogeneity of variances using the Shapiro-Wilk test ['stats' package (R Core Team 2018)] and Levene's test ['car' package (Fox and Weisberg 2011)], respectively. The one-way ANOVA ('stats' package) was used to determine whether any statistically significant differences exist between parameters. Pearson's correlation ['rcorr' function from 'Hmisc' package (Harrell Jr 2018)] was also calculated between these parameters. Due to the small number of populations, we pooled data for the two species when assessing correlations between the parameters analysed. Such an approach is legitimate because the sugars and AAs were the same in both species.

Prior to more sophisticated statistical analysis of AAs and sugars, a set of descriptive statistics ( $n$, mean, standard deviation, minimum, maximum, $95 \%$ mean confidence interval) was calculated for 21 AAs (two compounds were omitted due to single detection in seven populations; seven AAs were also omitted due to their absence in all populations) and three sugars with and without grouping by two plant species, i.e. P. bifolia, P. chlorantha. The data were further assessed for normality using the Shapiro-Wilk test ('stats' package). Data were considered to be normally distributed if $p \geq 0.05$ (Table 1S).

To check if a monotonic relationship exists between sugars, Spearman's rank correlations were calculated using the 'rcorr' function from the 'Hmisc' package and visualized as a matrix of coefficients and significance levels. Spearman's correlation was used because only one sugar (glucose) was considered to be normally distributed (Table $1 \mathrm{~S}$ ). To check for the existence of any monotonic relationships between the AAs, Spearman's correlations were also calculated using 'rcorr' function and visualized as a heatmap using the 'corrplot' package (Wei and Simko 2017). Spearman's correlation was used due to the fact that a few AAs were considered not normally distributed (Table $1 S$ ). All correlations were considered significant for $p<0.05$.

To detect the structure and general regularities in the relationships between AAs and to verify detected connections, principal component analysis (PCA) was used. A function named 'is.singular.matrix' from the package 'matrixcalc' (Novomestky 2015) was used to check if the correlation matrix of all AAs is singular: at least one of its rows (or one of the columns) is a linear combination of the other rows (or columns) of the matrix. Performing the Gauss Jordan elimination method on the Spearman correlation matrix ('rref' function from package 'pracma') (Borchers 2018) indicated that up to six AAs can be selected to produce a non-singular correlation matrix. An 
iterative algorithm was used to retrieve a combination of six AAs that has the highest Kaiser-Meyer-Olkin (KMO) test result value, i.e. measure of sampling adequacy (MSA), because its value close to 1 indicates that the sum of partial correlations is not large relative to the sum of the correlations and so factor analysis should yield distinct and reliable factors (Hair Jr et al. 2014). The following AAs: Asn, His, Cit, Orn, Lys and Sar were selected; their MSA was 0.8769 (Table 2S). To calculate KMO test, 'psych' package was used (Revelle 2018). According to Kaiser (1974), the received MSA value is meritorious; therefore, PCA could be performed. A function 'PCA' from the 'FactoMineR' package was used for this purpose (Lê et al. 2008). Values were normalized (scale. unit $=$ TRUE) and the remaining 15 AAs were assigned as supplementary variables (quanti.sup). A scree plot (Fig. 1S) was created using the 'fviz_eig' function from the 'factoextra' package (Kassambara and Mundt 2017). A decision was made that two factors, which explain $89.45 \%$ of the variance, are sufficient (Fig. 1S, Table 3S). A plot with the quality of the representation of AAs on the new dimensions (factors), created by PCA, (Fig. 2S) was prepared using the 'corrplot' package. Furthermore, PCA variables factor map and biplot were created using 'fviz_pca_var' and 'fviz_pca_biplot' functions, respectively (in the 'factoextra' package).

To analyse the effect of AAs on insect chemoreceptors, all identified and determined AAs were grouped into four classes: I. Asn, Gln, Ala, Cys, Gly, Ser, Thr and Tyr (no effect on the chemoreceptors of fly); II. Arg, Asp, Glu, His and Lys (inhibition of fly chemoreceptors); III. Pro and Hyp (stimulate the salt cell); IV. Ile, Leu, Met, Phe, Trp and Val (ability to stimulate the sugar cell) and presented as a ternary plot ('ggtern' package) (Hamilton and Ferry 2018).

\section{Results}

\section{Reproductive success}

Fruiting shaped at the lowest level in two $P$. bifolia populations (17.8\% in BC and $26.6 \%$ in POB1), while the highest was in BF P. chlorantha and in SMOL P. bifolia populations (almost 73.7\%, Table 1). The MRS was higher than FRS. The lowest was noted in the POB1 P. bifolia population (56.9\%); however, in the remaining populations, it ranged between $78.9 \%$ and $95.2 \%$. Statistically significant differences are reported for the levels of reproductive success between populations of $P$. bifolia (FRS: $F=60.128$; MRS: $F=9.274 ; p<0.001$ ) and $P$. chlorantha (FRS: $F=7.624$; MRS: $F=11.215 ; p<0.001)$.

\section{Nectar content and chemistry}

Nectar column length in spurs was different in populations of both species. The lowest nectar column among four P. bifolia populations was observed in BC population $(5.79 \pm 5.42 \mathrm{~mm})$, which was almost three times lower than that in the POG population with the highest nectar column $(15.94 \pm 5.05 \mathrm{~mm})$ (Table 1). In the case of P. chlorantha, the lowest nectar content was also noted in Białowieża National Park, in the BF population $(4.49 \pm 3.09 \mathrm{~mm})$, while the highest was in the BON population $(9.80 \pm 5.55 \mathrm{~mm})$. Significant differences of nectar column were noted between both $P$. chlorantha $(F=17.415, p<0.001)$ and $P$. bifolia populations $(F=32.292, p<0.001)$. Nectar column length influenced FRS in P. bifolia $(r=0.23, p<0.05)$ and MRS in $P$. chlorantha populations $(r=0.19, p<0.05)$.

Nectar in studied populations differed in sugar concentration. The highest $(1103.1 \mathrm{mM})$ was measured in the BF $P$. chlorantha population and the lowest $(430.7 \mathrm{mM})$ was measured in the POB1 P. bifolia population (Table 2). On average, nectar of $P$. chlorantha contained more sugars $(842.9 \mathrm{mM})$ than P. bifolia $(599.5 \mathrm{mM})$. The amount of sugars was relatively low and ranged between 90.4 and $206.8 \mathrm{mg} / \mathrm{mL}$ (Table 3). In both Platanthera species, sugar components found in the nectar included glucose, sucrose and fructose (at varying ratios) in each of the population (Tables 2, 3). In the studied populations, hexoses (glucose and fructose) dominated in the nectar, with higher concentrations of glucose being present except for the POG $P$. bifolia populations where the levels of glucose and sucrose were similar. The highest percentages of sucrose were found in two P. bifolia populations, POG and POB1, where sucrose/hexoses ratios equalled 0.59 and 0.43 , respectively. In the remaining populations, this ratio was in the range of 0.06-0.14 (Table 3). On average, the nectar of $P$. chlorantha contained more glucose and fructose in comparison to $P$. bifolia, while in the nectar of $P$. bifolia, there was about two times more sucrose than in $P$. chlorantha. No statistically significant correlations were found between the total sugar content in nectar and MRS or FRS. Fructose content positively influenced both MRS $(r=0.82, p<0.05)$ and FRS $(r=0.79, p<0.05)$. Moreover, no statistically significant correlations was found between glucose, fructose or sucrose (Table 4).

In general, 23 different AAs were detected in seven populations of both species, but the number of detected AAs differed in particular populations. The lowest (9 AAs) was in BC P. bifolia population, and the highest (20 AAs) was in POB $1 P$. bifolia and BON P. chlorantha populations (Table 5). Cys and GABA were present only in LIN P. chlorantha. However, seven AAs (Thr, Trp, Leu, Tyr, $\beta$-Ala, Tau, Nva) were detected neither in $P$. bifolia nor in $P$. chlorantha. Ser was a dominant AA in four populations: POG, SMOL, POB1 and BON (about 25\%). However, Sar dominated in 
Table 2 The concentration of sugars (mM) in Platanthera bifolia and P. chlorantha nectar with descriptive statistics

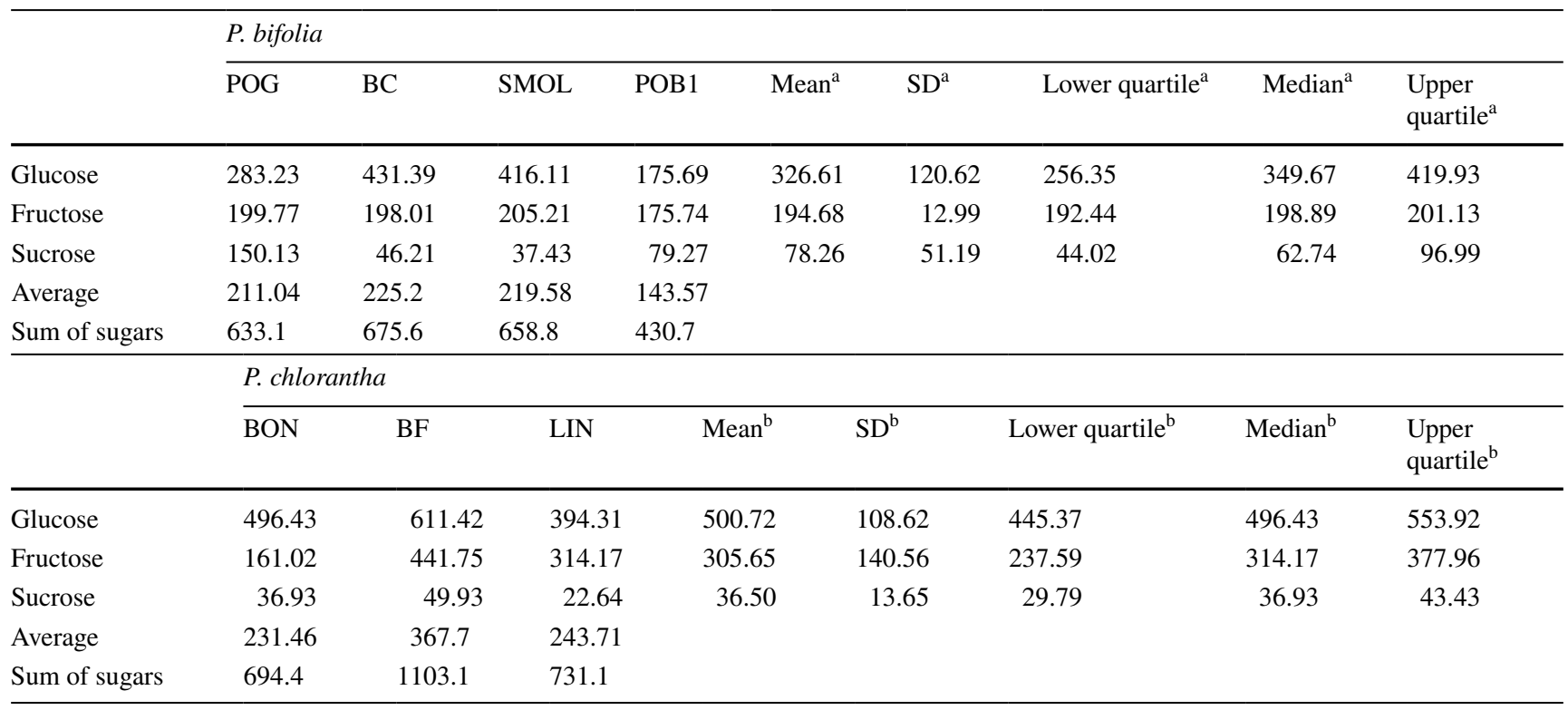

$S D$ standard deviation

${ }^{a}$ Calculated using a sugar value of POG, BC, SMOL, POB1 population

${ }^{\mathrm{b}}$ Calculated using a sugar value of BON, BF, LIN1 population

Table 3 The amount of sugars $(\mathrm{mg} / \mathrm{mL})$ in Platanthera bifolia and $P$. chlorantha nectar

\begin{tabular}{|c|c|c|c|c|c|c|c|}
\hline & \multicolumn{4}{|c|}{ P. bifolia } & \multicolumn{3}{|c|}{ P. chlorantha } \\
\hline & POG & $\mathrm{BC}$ & SMOL & POB1 & BON & $\mathrm{BF}$ & LIN \\
\hline Glucose & 51.03 & 77.72 & 74.96 & 31.65 & 89.44 & 110.15 & 71.04 \\
\hline Fructose & 35.99 & 35.67 & 36.97 & 31.66 & 29.01 & 79.58 & 56.60 \\
\hline Sucrose & 51.39 & 15.82 & 12.81 & 27.14 & 12.64 & 17.09 & 7.75 \\
\hline Sum of sugars & 138.40 & 129.21 & 124.75 & 90.45 & 131.08 & 206.83 & 135.39 \\
\hline Sugar content in nectar $(w / v)(\%)$ & 13.84 & 12.92 & 12.47 & 9.04 & 13.11 & 20.68 & 13.54 \\
\hline Ratio fructose/glucose & 0.71 & 0.46 & 0.49 & 1.00 & 0.32 & 0.72 & 0.80 \\
\hline Sucrose/(fructose + glucose) & 0.59 & 0.14 & 0.11 & 0.43 & 0.11 & 0.09 & 0.06 \\
\hline
\end{tabular}

Table 4 Correlation matrix for sugars $(n=7)$

\begin{tabular}{llll}
\hline & Glucose & Fructose & Sucrose \\
\hline Glucose & 1 & 0.21 & -0.36 \\
& & $p=0.6445$ & $p=0.4316$ \\
Fructose & 0.21 & 1 & -0.07 \\
& $p=0.6445$ & & $p=0.8790$ \\
Sucrose & -0.36 & -0.07 & 1 \\
& $p=0.4316$ & $p=0.8790$ & \\
\hline
\end{tabular}

Values indicate the Spearman's rank correlation coefficient with appropriate $p$ values

the remaining three populations: $\mathrm{BC}, \mathrm{BF}$ and LIN. Total AA concentrations negatively influenced pollinaria removal $(r=-0.79, p<0.05)$.
Among the AAs detected in the nectar of the Platanthera species, only Ile influenced reproductive success. A statistically significant negative selection of Ile on MRS and FRS ( $r=-0.89$ and $r=-0.83, p<0.05$, respectively) was observed.

Strong to 'perfect' positive rank correlations $\left(r_{\mathrm{s}}=0.77-1.00, p<0.05\right)$ were found between the same or different type (polar, acidic and polar, basic and polar, nonpolar and non-proteinogenic) AAs, e.g. Ser vs. Asp $r_{\mathrm{s}}=1$, Lys vs. Met $r_{\mathrm{s}}=1$, Arg vs. Orn $r_{\mathrm{s}}=0.83$ and Gly vs. Orn $r_{\mathrm{s}}=0.77$ (Fig. 1).

Negative scores for the first principal component (Dim1) indicate higher values of Hyp, Pro and AABA than mean values for all the studied populations although these values are positive for other AAs. Moreover, positive scores for the second principal component (Dim2) indicate values for Pro, Hyp, Gln, Phe, BABA, Asn, Ile, Orn and Val that are higher 
Table 5 The concentration of amino acids $(\mu \mathrm{M})$ in Platanthera bifolia and P. chlorantha nectar with descriptive statistics

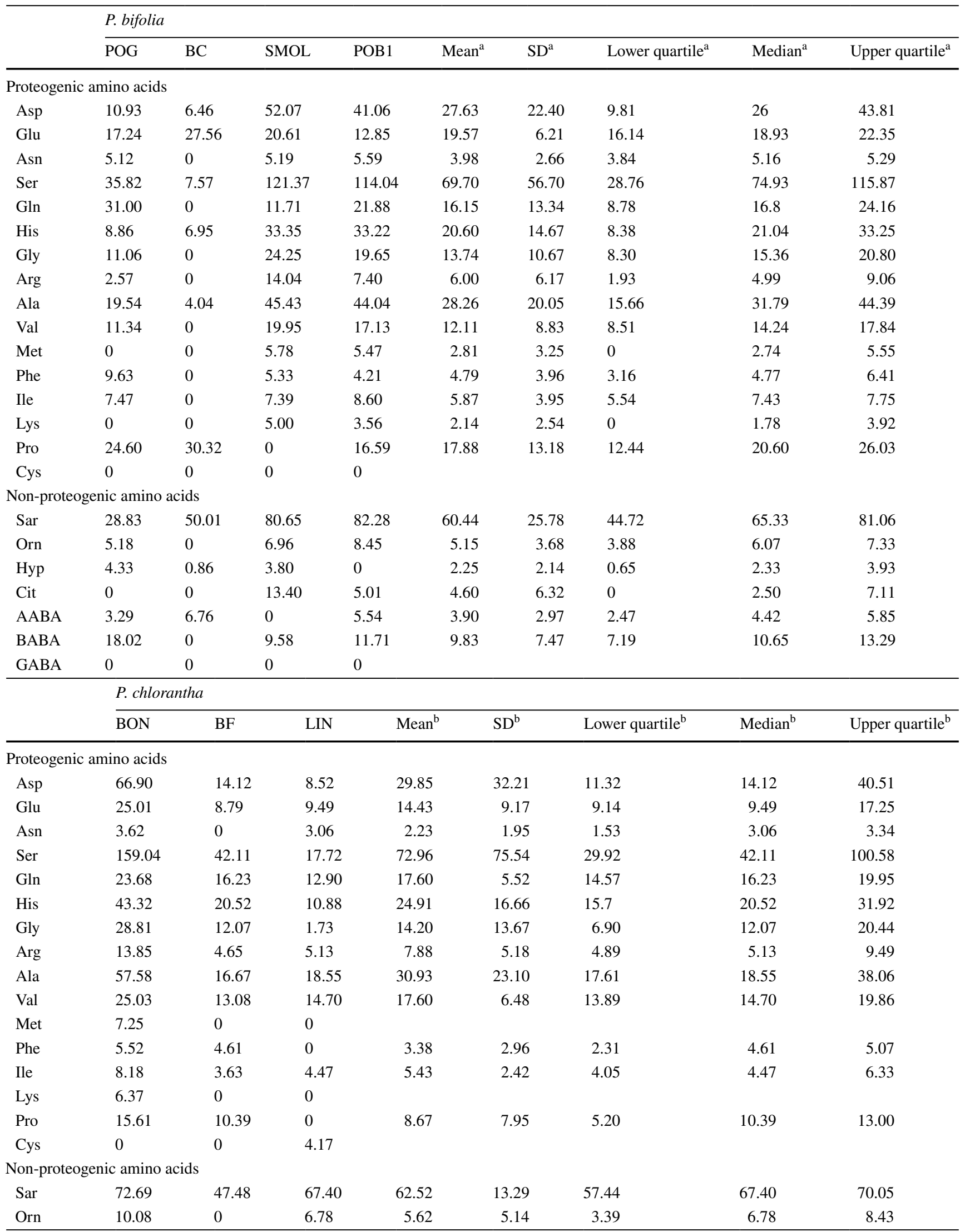


Table 5 (continued)

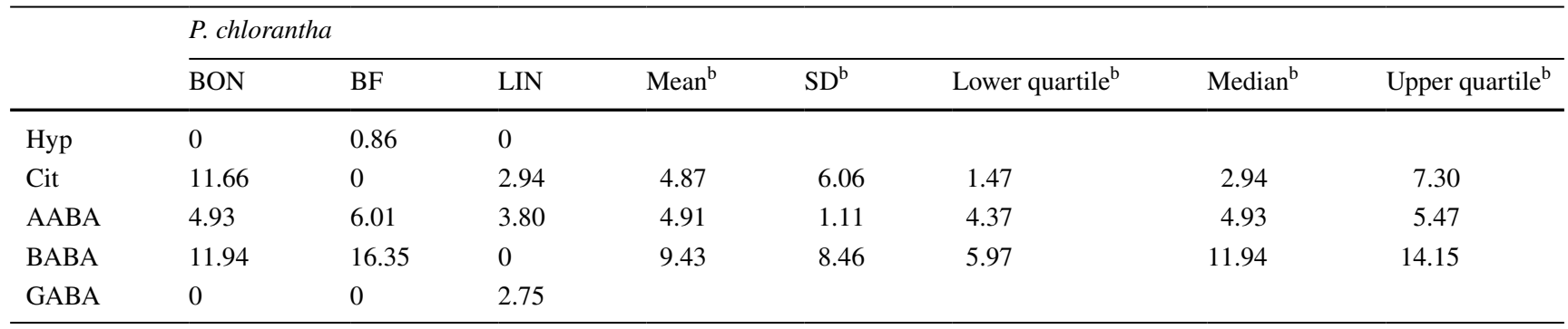

$S D$ standard deviation

${ }^{\mathrm{a} C}$ Calculated using an amino acid value of POG, BC, SMOL, POB1 population

${ }^{\mathrm{b}}$ Calculated using an amino acid value of BON, BF, LIN1 population

than mean values for all the populations, and are negative for the other AAs (Fig. 2). The PCA clustered SMOL, POB1 $P$. bifolia and BON $P$. chlorantha populations (all from SLP) together, which are loaded with Val, Ala, Gly, Ser, Met, Cit, Arg, Lys, Asp, Sar and His (the long vectors are associated with high levels of metabolites). These three populations are further characterized by negative loadings (low levels) for Pro and Hyp. The BC P. bifolia and BF P. chlorantha populations were also clustered because they have the highest number of AAs that are lower than average (positive loadings for all AAs, excluding AABA and Pro). The POG $P$. bifolia population is associated with high levels of Gln, BABA, Phe, Hyp and Pro. However, the LIN P. chlorantha population represents the best, having an average value for all AAs (the smallest distance from the origin of the coordinate system). Results of PCA show greater similarities in AA composition between populations from a given region than between populations of the same species.

Amino acids in nectars could present either a source for these compounds in the nutrition of the pollinators or the presence of AAs in nectar may contribute to its taste. The taste AAs are divided into four classes. Possible simulation of insect chemoreceptors by AAs in nectars have AAs from classes II, III and IV (Gardener and Gillman 2002; Nicolson and Thornburg 2007). The results indicate class II AAs dominate (chemoreceptor inhibitors) in both species (Fig. 3, Table 4S). In the LIN $P$. chlorantha population, AAs from taste class III (stimulation of salt cells) and in BC P. bifolia population AAs from taste class IV (stimulation of sugar cells) were absent. The participation of AAs from taste class III was on average three times higher in $P$. bifolia than in $P$ chlorantha, whereas participation of AAs from class IV was higher in $P$. chlorantha. Content of AAs from taste groups I and IV negatively influenced MRS in the populations studied (in both cases $r=-0.79, p<0.05$ ).

\section{Discussion}

Many studies have shown that plants have evolved different strategies to increase reproductive success. For example, producing nectar suitable for their potential pollinators, whose life history characters (e.g. growth and fecundity) depend on this food source (Baker and Baker 1983; Nicolson and Thornburg 2007; Petanidou 2007; Witt et al. 2013; Fowler et al. 2016). It is well known that although the concentration and composition of nectar are mainly connected with pollinator types, the constitution of nectar produced by plants of a given species varies in space and time (Pacini and Nepi 2007; Nocentini et al. 2013; Gijbels et al. 2014, 2015a, b).

Similar to other studies, we found differences in the nectar sugars, AA concentrations and compositions across $P$. bifolia and $P$. chlorantha populations (Tables 2, 5). The highest sugar content was found in the nectar from the BF $P$. chlorantha population and the highest AA content in the BON $P$. chlorantha population that exists in broadleaved forest on rich soils. On the other hand, the lowest levels of AAs in nectar were measured in two meadow populations of both species that are known as habitats with low nitrogen availability (Gijbels et al. 2014). Additionally, the low number of AAs (nine compounds) in the BC population may reflect the low levels of nitrogen in the soil. The sugar content of nectar was lowest in the POB1 P. bifolia population in a very high density community of young spruces. These results suggest the importance of habitat quality for nectar composition, which is in accordance with other studies. Higher AAs concentrations were previously reported in the nectar of Agrostemma githago and Gymnadenia conopsea that exist in habitats with more nutrient-rich soils by Gijbels et al. (2014) and Gardener and Gillman (2001), respectively. Also, higher nectar sugar content was reported in Allium ursinum by Farkas et al. (2012). The influence of soil composition on nectar AAs content and composition is well documented in experimental studies by Gijbels et al. (2015a). The importance of environmental conditions 


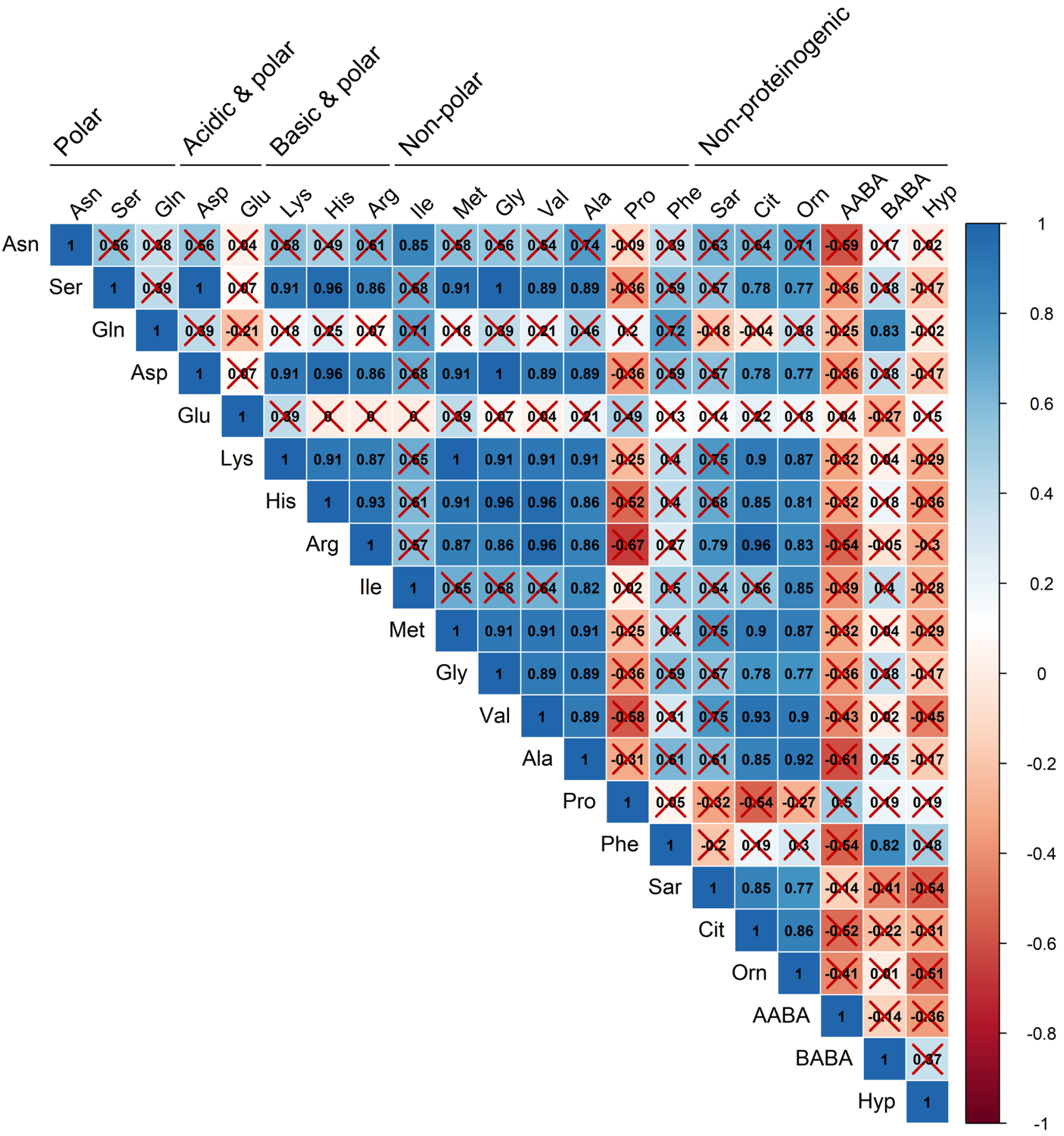

Fig. 1 Correlation heatmap for amino acids $(n=7)$. The coloured and labelled scale codes for the value of the Spearman's rank correlation coefficient $r_{\mathrm{s}}$. Positive correlations are blue while negative correlations are red. However, red crosses show insignificant correlations $(p \geq 0.05)$

also suggests that there are differences in Ser production between populations that exist in open habitats and under a tree canopy. In both meadow populations (one P. bifolia and one $P$. chlorantha) that have low levels of nitrogen in the soil, Ser participation in nectar was markedly lower. Gijbels et al. (2014) documented that production of Ser depends on soil nitrogen content. This result is also in accordance with
Nocentini et al. (2013), who found lower production of Ser in sunny places. To determine whether the nectar composition of two Platantherans is influenced by soil properties in the populations studied, further studies with soil analyses are needed.

Nectar quantity influenced FRS in P. bifolia and MRS in $P$. chlorantha populations. Increased RS could be 

profiles of $P$. bifolia and P. chlorantha populations, showing the first two dimensions/factors (Dim1-2) of PCA that together explain $89.45 \%$ of variance. Biplot vectors indicate strength and direction of factor loading for the first two factors. Vectors of active variables are in red; however, those of supplementary are in blue. Individuals (populations of orchids: POG, BC, SMOL, POB1, BON, BF, tinguish between $P$. bifolia and $P$. chlorantha populations
Fig. 2 Biplot of amino acid LIN) were colour coded to dis-

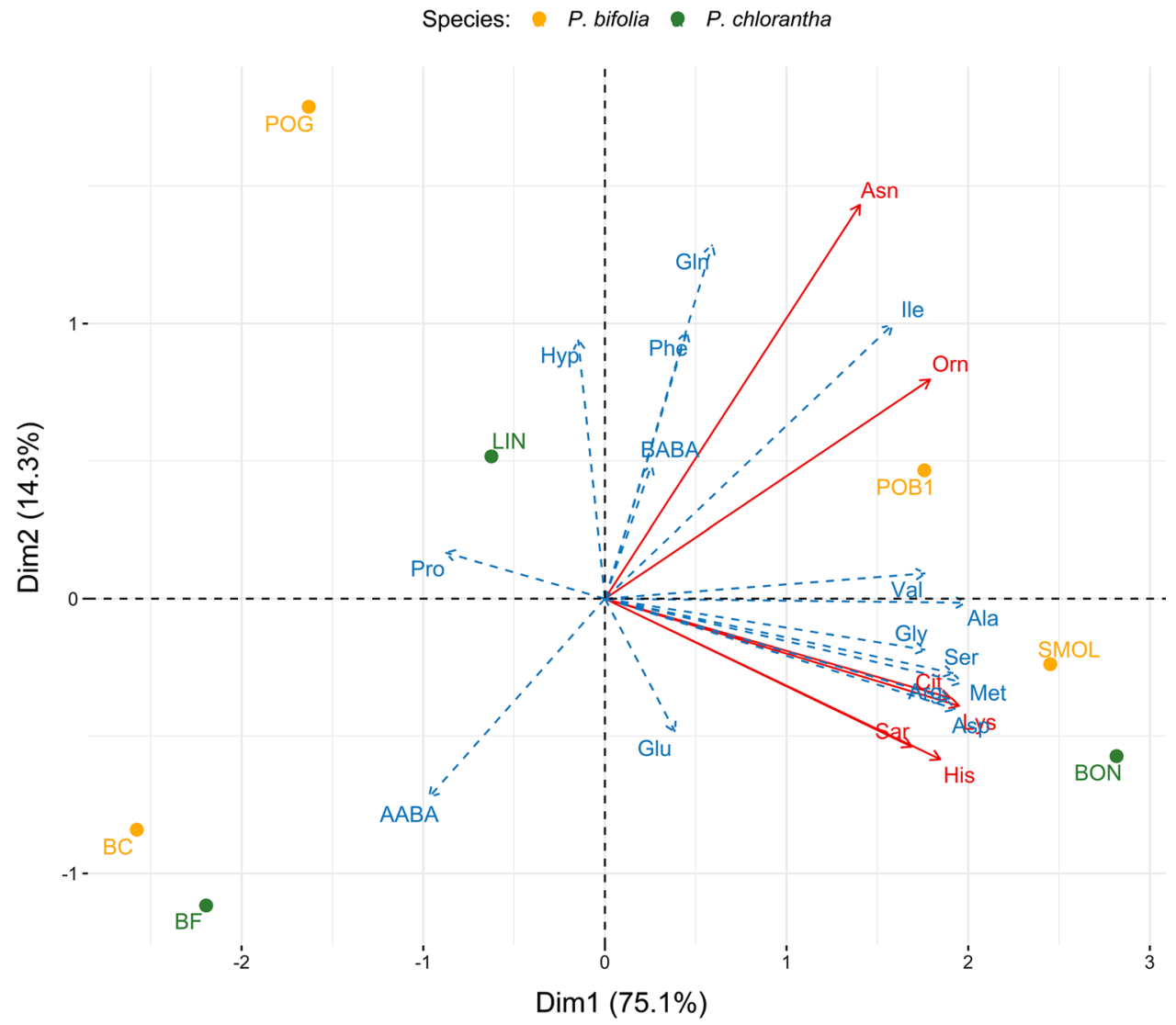

Fig. 3 Amino acid taste profiles for Platanthera populations: 1-POG, 2-BC, 3-SMOL, 4-POB1, 5-BON, 6-BF, 7-LIN. Classes represent the effect of AAs on insect chemoreceptors. Possible simulation of insect chemoreceptors by AAs in nectars indicates classes: II (Asp, Glu, His, Arg, Lys), III (Hyp, Pro) and IV (Val, Met, Trp, Phe, Ile, Leu). The first class of AAs (Asn, Gln, Ala, Cys, Gly, Ser, Thr, Tyr) has no effect on the chemoreceptors of fly (data not shown)

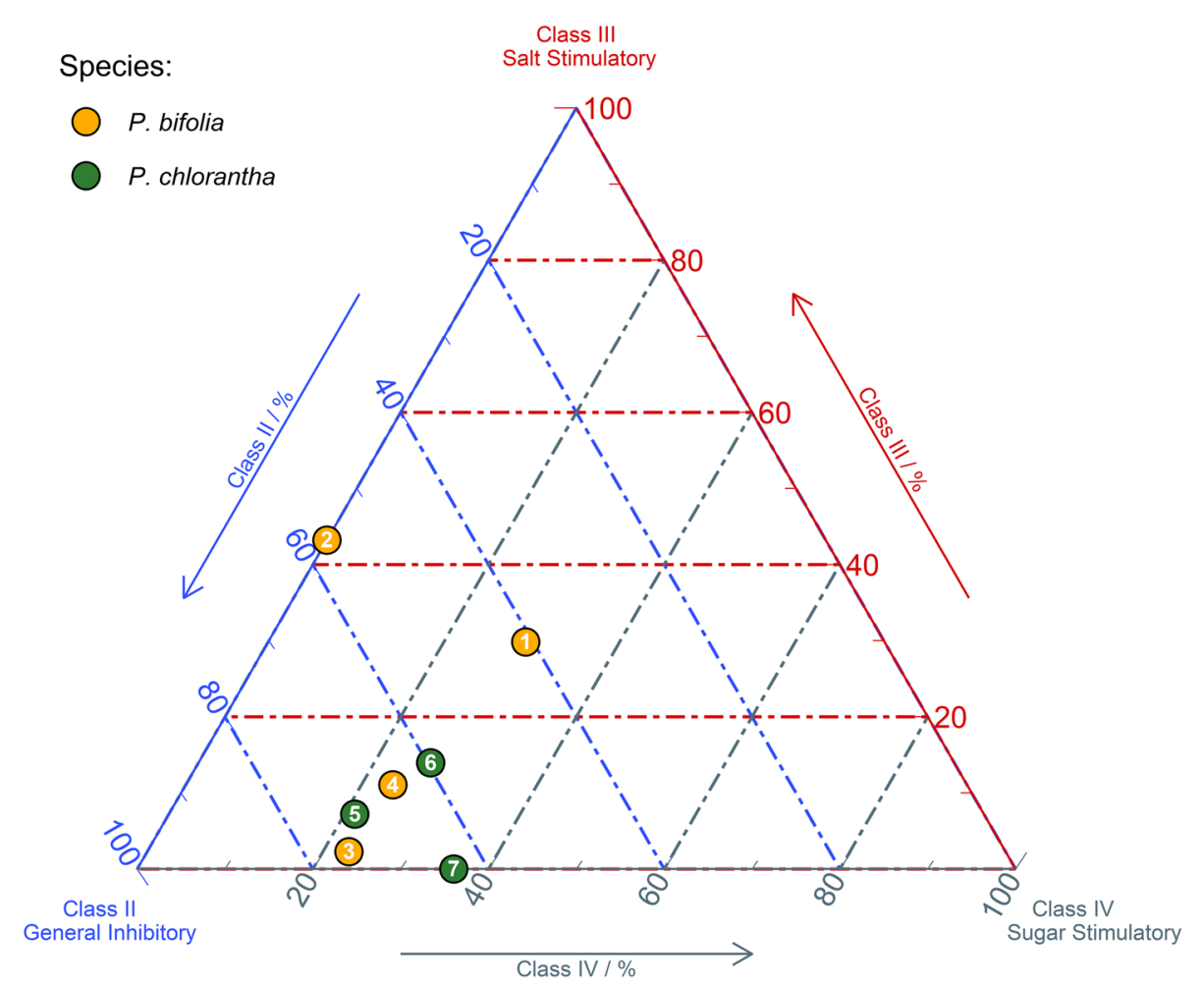


explained (as in other studies) by the longer visitation of inflorescences with more reward, i.e. higher nectar column in flowers (Hodges 1995; Maad and Reinhammar 2004). Simultaneously, such pollinator behaviour may have negative consequences such as increased autogamous pollination that causes decreased progeny fitness (de Jong et al. 1993; Jersáková and Johnson 2006). The relationship between nectar column length and the level of fruiting also suggests that in the studied populations, in which pollination is dominated by moths with relatively short tongues, there is a required higher level of nectar in spurs. Among the two main pollinator groups of $P$. bifolia and $P$. chlorantha, Sphingidae and Noctuidae, representatives of the second group usually possess shorter tongues. Most noctuids from the temperate zone have 10-20-mm-long tongues; sphingids' tongues may even exceed $40 \mathrm{~mm}$ (Boberg et al. 2014). On the other hand, large variations of the nectar column within populations provide the possibility that raising nectar by pollinators has a wider range of proboscis length than noctuids alone. The role of other factors that influence pollinator activity cannot be excluded. Flower morphology plays an important role in attracting pollinators and reproductive success because phenotypic selection is dependent on the mutual match between pollinator and flower traits (Moré et al. 2012). In long-spurred plants, such as Platantherans, one of the most important flower characters that influence pollinator activity and RS is spur length. Despite the fact that we did not measure this trait, its importance was documented for many plants, including Platanthera species (Maad 2000; Boberg and Ägren 2009; Nilsson 1988; Alexandersson and Johnson 2002; Little et al. 2005; Moré et al. 2012; Boberg et al. 2014). Moreover, the size of the spur is often linked to nectar production. It should also be noted that characteristics of individuals, such as their high and inflorescence size, as well as their spatial distribution, can influence pollinator activity and behaviour, which often translate to the level of RS (Maad 2000; Vallius and Salonen 2006; Duffy and Stout 2008).

The presented results confirm the reports of some authors that sucking feeders, including butterflies, prefer less concentrated nectar (with sugar concentrations of 20-25\%) than bees or birds (Kim et al. 2011; Tiedge and Lohaus 2017). Low concentrations of sugars in nectar for hawk moth-pollinated flowers (19\%) have also been reported (Pyke and Waser 1981; Baker and Baker 1982; Heyneman 1983). On the other hand, Willmer (2011) reported that the optimal feeding rates for Lepidoptera are at higher sugar concentration (35-45\%) and Josens and Farina (2001) found that hawk moths achieve peak intake at $34 \%$ sucrose. In both Platanthera species, sugars constituted around $13 \%$ of the nectar in five of the seven populations. In one $P$. chlorantha population, the sugar content exceeded $20 \%$ and in one P. bifolia population, the sugar content equalled only $9 \%$. These values are within the range recorded by Stpiczyńska and Pielecki (2002) for the P. chlorantha (27.5\% during the first days of secretion and $5.6 \%$ during the resorption stage). The percentage of sugars in $P$. chlorantha nectar during maximum secretion (19.37\%), which was measured by Stpiczyńska and Pielecki (2002), is almost identical to our measurements (20.68\%) in the BF population, which exists in the same type of community (broadleaved forest, Tilio-Carpinetum) as $P$. chlorantha plants used in Stpiczyńska's and Pielecki's experiments. In all populations of both Platanthera species, nectar was dominated by hexoses, which contrasts with the prevalent opinion that sucrose dominates in nectar (Petanidou 2005; Nepi et al. 2010; Antoń et al. 2017). This hypothesis was previously put forth in studies on orchids (Gottsberger et al. 1984; Pais et al. 1986; Stpiczyńska and Pielecki 2002; Gijbels et al. 2014). Even in Danish P. bifolia and P. chlorantha populations, Lindqvist et al. (2018), who was testing a novel technique, found that the nectar was dominated by sucrose. Stpiczyńska and Pielecki (2002) also found domination of sucrose in $P$. chlorantha nectar, while fructose and glucose occurred in a 1:1 ratio. Moreover, these authors noted that relations between particular sugars were the same in different phases of flower's lifespan. Our results also contrast with the statements of many authors that suggest high sucrose content in nectar is associated with a specialized pollination mode and that long-tubed flowers are adapted to the preference of long-tongued pollinators and use sucrose-dominated nectar (Baker and Baker 1990; Torres and Galetto 2002; Nicolson and Thornburg 2007; Johnson and Nicolson 2008; Witt et al. 2013; Tiedge and Lohaus 2017). Moreover, Baker and Baker (1983) observed that moths belong to a group of pollinators that prefer nectar that is rich in sucrose, and with sucrose:hexoses ratios that are $>0.5$. Also, Johnson and Nicolson (2008) point out that there is a clear distinction between nectar sucrose content of specialized (40-60\% of total sugar) and generalized (0-5\%) bird-pollinated species. In our studies, sucrose:hexoses ratios were $<0.5$ in all populations. We did not find selection on the total sugar content at the population level, which may indicate that carbon content in soils (where both species exist) is enough to produce the required nectar components. It was documented that nutrient availability in soil influences plant metabolism and nectar production (Gardener and Gillman 2001). Some authors found that nectar sugar concentration increases with increasing soil organic matter (Baude et al. 2011; Gijbels et al. 2014). Among three sugars detected, only an increase in fructose content in populations increased both MRS and FRS ( $r=0.82$ and $r=0.79$, respectively). Fructose may be preferred by pollinators due to its easier absorption and/or lower viscosity, thus allowing better flux (Heyneman 1983). Preferring lower sugar concentration by at least some Platanthera species pollinators reveals that some of them possess the ability to dilute 
more concentrated nectar through a salivating technique, e.g. Autographa gamma from the Noctuidae (Wei et al. 1998).

Despite the fact that many data document the importance of AAs in nectar for pollinators attraction and their behaviour on the grounds of plant fitness (Baker and Baker 1986; Gijbels et al. 2014), some studies do not support that there is selection on the AAs content of nectar (Gijbels et al. 2015a, b). All correlations, which were noted between AA characteristics and the level of reproductive success, were negative and concerned almost exclusively MRS parameters. Increases in total AA content caused decreased levels of pollinaria removal in populations of $P$. bifolia and $P$. chlorantha, which suggests that moths pollinating both Platanthera species prefer nectar with lower AA concentrations in contrast to some Lepidoptera preferring nectars with higher AA concentrations. It is well known that some AAs influence nectar taste, thus attracting or discouraging visitors (Gijbels et al. 2015a, b). Our results suggest that pollinators of Platanthera species are also sensitive to nectar taste. An interesting finding is that AAs from taste classes I and IV have a negative influence on MRS. Negative selection on Ile content and increases of this AA in populations caused decreases in both MRS and FRS. Insects can avoid or reject nectar with an overabundance of Ile because it can change the nectar taste to one that is not preferred by them. An excess in Ile may inhibit activity of other AAs that are important for insects' metabolism (Gardener and Gillman 2002).

Some non-proteogenic AAs, such as Sar, Cit, Orn, Hyp, AABA, BABA, and GABA, have been found in the nectar of $P$. bifolia and/or $P$. chlorantha (Table 5). Although the role of non-proteogenic AAs is still unclear in nectar, they have different functions in plants that include antiherbivory, antimicrobial and allelochemical activities, protection against stress, signalling, nitrogen storage, and they are used as toxins against invertebrates and vertebrates (Bell 2003; Vranová et al. 2010; Nepi et al. 2012). They also play an important role in modulating insect behaviour. For example, GABA and $\beta$-Ala influence insect nervous system and muscle activity (Nepi 2014; Felicioli et al. 2018). In the nectar of some plants (e.g. Nicotiana alata and N. plumbaginifolia), GABA dominates, constituting even $39 \%$ of the total AAs (Kaczorowski et al. 2005). Taking into account the quantity of particular AAs in Platanthera nectar, Sar has the greatest importance, reaching (on average) $>20 \%$ in both species and even exceeding one-third of the total AAs in two populations (one of each species).

The next three AAs that exceeded $10 \%$ of the total AAs content are Pro, Ser and Glu and the three AAs that constitute ca. 7-8\% are Asp, His and Ala. Many of these AAs function as nutritional sources. For instance, Ala and Ser influence insects' growth (Gijbels et al. 2014) and Glu,
Ser and Asp influence pollinators' behaviour. Additionally, Gln is useful for energetically expensive flight (Gardener and Gillman 2002; Gijbels et al. 2015b). One of the most common AAs in plant nectar, including the species studied here, is Pro (on average Pro accounts for $10 \%$ of all AAs in both species). Pro is the dominant AA in some species (Carter et al. 2006; Nepi et al. 2012), but in Gymnadenia conopsea, an orchid that is pollinated by diurnal and nocturnal Lepidoptera, Pro has only a small contribution (Gijbels et al. 2014) and is absent in Oenothera species (Antoń et al. 2017). The accumulation of Pro is commonly interpreted as a plant's answer to stress factors, such as drought or frost (Carter et al. 2006). Pro plays an important role in nectar taste because it can trigger the normal insects' salt-receptor neurons, which can initiate feeding (Heil 2011; Willmer 2011; Nocentini et al. 2013). Moreover, Pro may be an important energy source due to its utilization over glucose and its fast production of ATP (Carter et al. 2006; Gijbels et al. 2014; Nepi 2014). Pro may be especially important in the context of low sugar concentrations in nectar from the two Platanthera species. Taking into account the positive influences of Pro, two questions, which are in contradiction with the importance of Pro for pollinators' attraction, arise: why is this AA absent in the two populations studied by us? And, why was the lowest fruiting noted in the P. bifolia BC population, which had the most abundant Pro in its nectar (21.6\%)?

This study documents for the first time the sugar and AA composition in the nectar of natural populations of two sister species, $P$. bifolia and $P$. chlorantha, which are the most common representatives of this genus in Europe in the context of reproductive success. Although the main sugar and AA components of $P$. bifolia and $P$. chlorantha nectar are similar, detailed comparisons reveal some differences. The total sugar content in nectar was higher in $P$. chlorantha. Moreover, although hexoses dominated in the nectar from both species, the nectar from P. chlorantha contained more glucose and fructose than P. bifolia. The sucrose content was over two times higher in P. bifolia. Nectar of these two species also differed according to their sucrose:hexoses ratio. The ratio in $P$ bifolia is over threefold higher than $P$. chlorantha. The number of AAs detected and their total content was approximately at the same level in both species. Similarly, no species-specific AAs were reported. On the other hand, the ratio of AA sum to sugar sum was higher in P. bifolia. Additionally, the presence of AAs from taste class III was found to be three times higher in $P$. bifolia than in $P$. chlorantha, while the percentage of AAs from taste class IV was higher in $P$. chlorantha. To verify if the above-mentioned differences are truly species specific, or, if these results are simply due to the particular populations studied, further studies are needed. These studies should include more populations 
from other habitats and regions. Similarly, to assess the needs and preferences of $P$. chlorantha and $P$. bifolia pollinators to nectar offered by these orchids, additional studies are also necessary and should include nectar analysis at the level of individuals.

Author contribution statement EB conceived the study and wrote the manuscript. $\mathrm{AB}$ performed statistical analysis and the nectar analysis. $\mathrm{EB}$ and $\mathrm{AB}$ read and approved the final manuscript.

Acknowledgements We thank Edyta Jermakowicz, Beata Ostrowiecka, Paweł Mirski, Izabela Tałałaj and Ada Wróblewska for their help in the field. We thank Magdalena Fiłoc and Magdalena Chmur for their help in the laboratory. We also thank Adam Bajguz and Jarosław Kotowicz for statistical consultation. This work was funded by the Ministry of Science and Higher Education as part of subsidies for maintaining research potential awarded to the Faculty of Biology and Chemistry of the University of Bialystok.

\section{Compliance with ethical standards}

Conflict of interest The authors declare that the research was conducted in the absence of any commercial relationships, and there was no potential conflict of interest.

Open Access This article is distributed under the terms of the Creative Commons Attribution 4.0 International License (http://creativeco mmons.org/licenses/by/4.0/), which permits unrestricted use, distribution, and reproduction in any medium, provided you give appropriate credit to the original author(s) and the source, provide a link to the Creative Commons license, and indicate if changes were made.

\section{References}

Ackerman JD, Rodriguez-Robles JA, Melendez EJ (1994) A meager nectar offering by an epiphytic orchid is better than nothing. Biotropica 26:44-49. https://doi.org/10.2307/2389109

Adler LS (2000) The ecological significance of toxic nectar. Oikos 91:409-420. https://doi.org/10.1034/j.1600-0706.2000.910301.x

Adler LS, Irwin RE (2005) Ecological costs and benefits of defenses in nectar. Ecology 86:2968-2978. https://doi.org/10.1890/05-0118

Adler LS, Irwin RE (2012) Nectar alkaloids decrease pollination and female reproduction in a native plant. Oecologia 168:1033-1041. https://doi.org/10.1007/s00442-011-2153-3

Alexandersson R, Johnson SD (2002) Pollinator-mediated selection on flower-tube length in a hawkmoth-pollinated Gladiolus (Iridaceae). Proc Biol Sci 269:631-636. https://doi.org/10.1098/ rspb.2001.1928

Antoń S, Komoń-Janczara E, Denisow B (2017) Floral nectary, nectar production dynamics and chemical composition in five nocturnal Oenothera species (Onagraceae) in relation to floral visitors. Planta 246:1051-1067. https://doi.org/10.1007/s0042 5-017-2748-y

Baker HG (1977) Non-sugar chemical constituents of nectar. Apidologie 8:349-356. https://doi.org/10.1051/apido:19770405

Baker HG, Baker I (1982) Chemical constituents of nectar in relation to pollination mechanisms and phylogeny. In: Nitecki MH (ed)
Biochemical aspects of evolutionary biology. University of Chicago Press, Chicago, pp 131-137

Baker HG, Baker I (1983) Floral nectar sugar constituents in relation to pollinator type. In: Jones CE, Little RJ (eds) Handbook of experimental pollination biology. Van Nostrand Reinhold Company Inc., New York, pp 131-141

Baker HG, Baker I (1986) The occurrence and significance of amino acids in floral nectar. Plant Syst Evol 151:175-186. https://doi. org/10.1007/bf02430273

Baker HG, Baker I (1990) The predictive value of nectar chemistry to the recognition of pollinator types. Isr J Bot 39:157-166. https ://doi.org/10.1080/0021213X.1990.10677140

Baracchi D, Marples A, Jenkins AJ, Leitch AR, Chittka L (2017) Nicotine in floral nectar pharmacologically influences bumblebee learning of floral features. Sci Rep 7:1951. https://doi. org/10.1038/s41598-017-01980-1

Bateman RN, Sexton R (2008) Is spur length of Platanthera species in the British Isles adaptively optimized or an evolutionary red herring? Watsonia 27:1-21

Bateman RM, James KE, Rudall PJ (2012) Contrast in levels of morphological versus molecular divergence between closely related Eurasian species of Platanthera (Orchidaceae) suggests recent evolution with a strong allometric component. New J Bot 2:110 148. https://doi.org/10.1179/2042349712Y.0000000013

Baude M, Leloup J, Suchail S, Allard B, Benest D, Mériguet J, Nunan N, Dajoz I, Raynaud X (2011) Litter inputs and plant interactions affect nectar sugar content. J Ecol 99:828-837. https://doi.org/1 0.1111/j.1365-2745.2011.01793.x

Bell EA (2003) Nonprotein amino acids of plants: significance in medicine, nutrition, and agriculture. J Agric Food Chem 51:28542865. https://doi.org/10.1021/jf020880w

Boberg E, Ägren J (2009) Despite their apparent integration, spur length but not perianth size affects reproductive success in the moth-pollinated orchid Platanthera bifolia. Funct Ecol 23:10221028. https://doi.org/10.1111/j.1365-2435.2009.01595.x

Boberg E, Alexandersson R, Jonsson M, Maad J, Ägren J, Nilsson LA (2014) Pollinator shifts and the evolution of spur length in the moth-pollinated orchid Platanthera bifolia. Ann Bot 113:267275. https://doi.org/10.1093/aob/mct217

Borchers HW (2018) pracma: practical numerical math functions (R package version 2.1.8) (2018) https://CRAN.R-project.org/packa ge $=$ pracma. Accessed 16 Oct 2018

Brzosko E (2003) The dynamics of island populations of Platanthera bifolia in the Biebrza National Park (NE Poland). Ann Bot Fenn 40:243-253

Brzosko E, Wróblewska A (2013) Genetic diversity of nectar-rewarding Platanthera chlorantha and nectarless Cephalanthera rubra. Bot J Linn Soc 171:751-763. https://doi.org/10.1111/boj.12025

Brzosko E, Wróblewska A, Tałałaj I, Adamowski W (2009) Patterns of genetic diversity in Platanthera bifolia (Orchidaceae) with respect to life history traits and recent range expansion. Folia Geobot 44:131-144. https://doi.org/10.1007/s12224-009-9033-1

Carter C, Shafir S, Yehonatan L, Palmer RG, Thornburg R (2006) A novel role for proline in plant floral nectars. Naturwissenschaften 93:72-79. https://doi.org/10.1007/s00114-005-0062-1

Claessens J, Kleynen J (2011) The flower of the European orchid. Form and function. Claessens \& Kleynen, Guelle (privately published)

de Jong TJ, Waser NM, Klinkhamer PGL (1993) Geitonogamy: the neglected side of selfing. Trends Ecol Evol 8:321-325. https:// doi.org/10.1016/0169-5347(93)90239-L

Duffy KJ, Stout JC (2008) The effects of plant density and nectar reward on bee visitation to the endangered orchid Spiranthes romanzoffiana. Acta Oecologica 34:131-138. https://doi. org/10.1016/j.actao.2008.04.007 
Duffy KJ, Stout JC (2011) Effects of conspecific and heterospecific floral density on the pollination of two related rewarding orchids. Plant Ecol 212:1397-1406. https://doi.org/10.1007/s1125 8-011-9915-1

Durka W, Baum A, Michalski SG, Baum H (2017) Darwin's legacy in Platanthera: are there more than two species in the Platanthera bifolia/chlorantha group? Plant Syst Evol 303:419-431. https:// doi.org/10.1007/s00606-016-1381-8

Esposito F, Merckx T, Tyteca D (2017) Noctuid moths as potential hybridization agents for Platanthera orchids. Lankesteriana 17:383-393

Esposito F, Vereecken NJ, Gammella M, Rinaldi R, Laurent P, Tyteca D (2018) Characterization of sympatric Platanthera bifolia and Platanthera chlorantha (Orchidaceae) populations with intermediate plants. PeerJ. https://doi.org/10.7717/peerj.4256

Farkas Á, Molnár R, Morschhauser T, Hahn I (2012) Variation in nectar volume and sugar concentration of Allium ursinum L. ssp. ucrainicum in three habitats. Sci World J 2012:7. https://doi. org/10.1100/2012/138579

Felicioli A, Sagona S, Galloni M, Bortolotti L, Bogo G, Guarnieri M, Nepi M (2018) Effects of nonprotein amino acids on survival and locomotion of Osmia bicornis. Insect Mol Biol 27:556-563. https://doi.org/10.1111/imb.12496

Fowler RE, Rotheray EL, Goulson D (2016) Floral abundance and resource quality influence pollinator choice. Insect Conserv Divers 9:481-494. https://doi.org/10.1111/icad.12197

Fox J, Weisberg S (2011) An R companion to applied regression, 2nd edn. SAGE Publications Inc, Thousand Oaks

Gardener MC, Gillman MP (2001) The effects of soil fertilizer on amino acids in the floral nectar of corncockle, Agrostemma githago (Caryophyllaceae). Oikos 92:101-106. https://doi.org /10.1034/j.1600-0706.2001.920112.x

Gardener MC, Gillman MP (2002) The taste of nectar-a neglected area of pollination ecology. Oikos 98:552-557. https://doi.org /10.1034/j.1600-0706.2002.980322.x

Gijbels P, Van den Ende W, Honnay O (2014) Landscape scale variation in nectar amino acid and sugar composition in a Lepidoptera pollinated orchid species and its relation with fruit set. $\mathbf{J}$ Ecol 102:136-144. https://doi.org/10.1111/1365-2745.12183

Gijbels P, Ceulemans T, Van den Ende W, Honnay O (2015a) Experimental fertilization increases amino acid content in floral nectar, fruit set and degree of selfing in the orchid Gymnadenia conopsea. Oecologia 179:785-795. https://doi.org/10.1007/ s00442-015-3381-8

Gijbels P, Van den Ende W, Honnay O (2015b) Phenotypic selection on nectar amino acid composition in the Lepidoptera pollinated orchid species Gymnadenia conopsea. Oikos 124:421-427. https://doi.org/10.1111/oik.01528

Gottsberger G, Schrauwen J, Linskens HF (1984) Amino acids and sugars in nectar, and their putative evolutionary significance. Plant Syst Evol 145:55-77. https://doi.org/10.1007/bf009 84031

Hair JF Jr, Black WC, Babin BJ, Anderson RE (2014) Multivariate data analysis. Pearson Education Limited, Edinburgh Gate

Hamilton NE, Ferry M (2018) ggtern: ternary diagrams using ggplot2. J Stat Softw 87:1-17. https://doi.org/10.18637/jss.v087.c03

Harrell FE Jr (2018) Hmisc: Harrell miscellaneous (R package version 4.1-1). https://CRAN.R-project.org/package $=$ Hmisc. Accessed 3 Jan 2018

Heil M (2011) Nectar: generation, regulation and ecological functions. Trends Plant Sci 16:191-200. https://doi.org/10.1016/j. tplants.2011.01.003

Heyneman AJ (1983) Optimal sugar concentrations of floral nectarsdependence on sugar intake efficiency and foraging costs. Oecologia 60:198-213. https://doi.org/10.1007/bf00379522
Hodges SA (1995) The influence of nectar production on hawkmoth behavior, self pollination, and seed production in Mirabilis multiflora (Nyctaginaceae). Am J Bot 82:197-204. https://doi. org/10.1002/j.1537-2197.1995.tb11488.x

Hultén E, Fries M (1986) Atlas of North European vascular plant. North of the tropic of cancer. Koeltz Scientific Books, Königstein

Jersáková J, Johnson SD (2006) Lack of floral nectar reduces selfpollination in a fly-pollinated orchid. Oecologia 147:60-68. https ://doi.org/10.1007/s00442-005-0254-6

Johnson SD, Nicolson SW (2008) Evolutionary associations between nectar properties and specificity in bird pollination systems. Biol Lett 4:49-52. https://doi.org/10.1098/rsbl.2007.0496

Josens RB, Farina WM (2001) Nectar feeding by the hovering hawk moth Macroglossum stellatarum: intake rate as a function of viscosity and concentration of sucrose solutions. J Comp Physiol A 187:661-665. https://doi.org/10.1007/s00359-001-0238-x

Kaczorowski RL, Gardener MC, Holtsford TP (2005) Nectar traits in Nicotiana section Alatae (Solanaceae) in relation to floral traits, pollinators, and mating system. Am J Bot 92:1270-1283. https ://doi.org/10.3732/ajb.92.8.1270

Kaiser HF (1974) An index of factorial simplicity. Psychometrika 39:31-36. https://doi.org/10.1007/bf02291575

Kassambara A, Mundt F (2017) factoextra: Extract and visualize the results of multivariate data analyses ( $\mathrm{R}$ package version 1.0.5). https://CRAN.R-project.org/package=factoextra. Accessed 22 Aug 2017

Kessler D, Gase K, Baldwin IT (2008) Field experiments with transformed plants reveal the sense of floral scents. Science 321:1200-1202. https://doi.org/10.1126/science.1160072

Kim W, Gilet T, Bush JW (2011) Optimal concentrations in nectar feeding. Proc Natl Acad Sci USA 108:16618-16621. https:// doi.org/10.1073/pnas.1108642108

Lê S, Josse J, Husson F (2008) FactoMineR: an R package for multivariate analysis. J Stat Softw 25:1-18. https://doi.org/10.18637 /jss.v025.i01

Leiss KA, Klinkhamer PGL (2005) Spatial distribution of nectar production in a natural Echium vulgare population: implications for pollinator behaviour. Basic Appl Ecol 6:317-324. https:// doi.org/10.1016/j.baae.2005.02.006

Lindqvist DN, Pedersen HAE, Rasmussen LH (2018) A novel technique for determination of the fructose, glucose and sucrose distribution in nectar from orchids by HPLC-ELSD. J Chromatogr B 1081:130-134. https://doi.org/10.1016/j.jchro mb.2018.02.019

Little KJ, Dieringer G, Romano M (2005) Pollination ecology, genetic diversity and selection on nectar spur length in Platanthera lacera (Orchidaceae). Plant Spec Biol 20:183-190. https://doi.org/10.1111/j.1442-1984.2005.00137.x

Maad J (2000) Phenotypic selection in hawkmoth-pollinated Platanthera bifolia: targets and fitness surfaces. Evolution 54:112123. https://doi.org/10.1111/j.0014-3820.2000.tb00012.x

Maad J, Alexandersson R (2004) Variable selection in Platanthera bifolia (Orchidaceae): phenotypic selection differed between sex functions in a drought year. J Evol Biol 17:642-650. https ://doi.org/10.1111/j.1420-9101.2004.00703.x

Maad J, Nilsson LA (2004) On the mechanism of floral shifts in speciation: gained pollination efficiency from tongue- to eye-attachment of pollinia in Platanthera (Orchidaceae). Biol J Linn Soc 83:481-495. https://doi.org/10.111 $1 / \mathrm{j} .1095-8312.2004 .00406 . x$

Maad J, Reinhammar LG (2004) Incidence of geitonogamy differs between two populations in the hawkmoth-pollinated Platanthera bifolia (Orchidaceae). Can J Bot 82:1586-1593. https:// doi.org/10.1139/B04-124

Manson JS, Cook D, Gardner DR, Irwin RE (2013) Dosedependent effects of nectar alkaloids in a montane 
plant-pollinator community. J Ecol 101:1604-1612. https://doi. org/10.1111/1365-2745.12144

Martins DJ, Johnson SD (2007) Hawkmoth pollination of aerangoid orchids in Kenya, with special reference to nectar sugar concentration gradients in the floral spurs. Am J Bot 94:650-659. https ://doi.org/10.3732/ajb.94.4.650

Mevi-Schütz J, Erhardt A (2005) Amino acids in nectar enhance butterfly fecundity: a long-awaited link. Am Nat 165:411-419. https ://doi.org/10.1086/429150

Moré M, Amorim FW, Benitez-Vieyra S, Medina AM, Sazima M, Cocucci AA (2012) Armament imbalances: match and mismatch in plant-pollinator traits of highly specialized long-spurred orchids. PLoS One 7:e41878. https://doi.org/10.1371/journ al.pone. 0041878

Mõtlep M, Tali K, Ilves A, Ounap E, Kull T (2018) Management affects the pollinator abundance but not the reproductive success of butterfly orchids. Plant Ecol 219:1329-1339. https://doi. org/10.1007/s11258-018-0882-7

Neiland MRM, Wilcock CC (1998) Fruit set, nectar reward, and rarity in the Orchidaceae. Am J Bot 85:1657-1671. https://doi. org/10.2307/2446499

Nepi M (2014) Beyond nectar sweetness: the hidden ecological role of non-protein amino acids in nectar. J Ecol 102:108-115. https:// doi.org/10.1111/1365-2745.12170

Nepi M, Selvi F, Pacini E (2010) Variation in nectar-sugar profile of Anchusa and allied genera (Boraginaceae). Bot J Linn Soc 162:616-627. https://doi.org/10.1111/j.1095-8339.2010.01036.x

Nepi M, Soligo C, Nocentini D, Abate M, Guarnieri M, Cai G, Bini L, Puglia M, Bianchi L, Pacini E (2012) Amino acids and protein profile in floral nectar: much more than a simple reward. Flora 207:475-481. https://doi.org/10.1016/j.flora.2012.06.002

Nepi M, Grasso DA, Mancuso S (2018) Nectar in plant-insect mutualistic relationships: from food reward to partner manipulation. Front Plant Sci 9:1063. https://doi.org/10.3389/fpls.2018.01063

Nicolson SW, Thornburg RW (2007) Nectar chemistry. In: Nicolson SW, Nepi M, Pacini E (eds) Nectaries and nectar. Springer Netherlands, Dordrecht, pp 215-264. https://doi. org/10.1007/978-1-4020-5937-7_5

Nilsson LA (1983) Processes of isolation and introgressive interplay between Platanthera bifolia (L.) Rich and Platanthera chlorantha (Custer) Reichb. (Orchidaceae). Bot J Linn Soc 87:325-350. https://doi.org/10.1111/j.1095-8339.1983.tb00997.x

Nilsson LA (1985) Characteristics and distribution of intermediates between Platanthera bifolia and Platanthera chlorantha (Orchidaceae) in the Nordic countries. Nord J Bot 5:407-419

Nilsson LA (1988) The evolution of flowers with deep corolla tubes. Nature 334:147-149. https://doi.org/10.1038/334147a0

Nocentini D, Pacini E, Guarnieri M, Martelli D, Nepi M (2013) Intrapopulation heterogeneity in floral nectar attributes and foraging insects of an ecotonal Mediterranean species. Plant Ecol 214:799-809. https://doi.org/10.1007/s11258-013-0204-z

Novomestky F (2015) matrixcalc: collection of functions for matrix calculations (R package version 1.0-3). https://CRAN.R-proje ct.org/package $=$ matrixcalc. Accessed 20 Feb 2015

Pacini E, Nepi M (2007) Nectar production and presentation. In: Nicolson SW, Nepi M, Pacini E (eds) Nectaries and Nectar. Springer Netherlands, Dordrecht, pp 167-214. https://doi. org/10.1007/978-1-4020-5937-7_4

Pais M, Neves H, Vasconcelos MP (1986) Amino acid and sugar content of the nectar exudate from Limodorum abortivum (Orchidaceae). Comparison with Epipactis atropurpurea nectar composition. Apidologie 17:125-136. https://doi.org/10.1051/apido :19860205

Parachnowitsch AL, Manson JS, Sletvold N (2019) Evolutionary ecology of nectar. Ann Bot 123:247-261. https://doi.org/10.1093/ aob/mcy 132
Petanidou T (2005) Sugars in Mediterranean floral nectars: an ecological and evolutionary approach. J Chem Ecol 31:1065-1088. https ://doi.org/10.1007/s10886-005-4248-y

Petanidou T (2007) Ecological and evolutionary aspects of floral nectars in Mediterranean habitats. In: Nicolson SW, Nepi M, Pacini E (eds) Nectaries and nectar. Springer Netherlands, Dordrecht, pp 343-375. https://doi.org/10.1007/978-1-4020-5937-7_8

Pyke GH (2016) Floral nectar: pollinator attraction or manipulation? Trends Ecol Evol 31:339-341. https://doi.org/10.1016/j. tree.2016.02.013

Pyke GH, Waser NM (1981) The production of dilute nectars by hummingbird and honeyeater flowers. Biotropica 13:260-270. https ://doi.org/10.2307/2387804

R Core Team (2018) R: a language and environment for statistical computing ( $\mathrm{R}$ version 3.5.2, Eggshell Igloo). $\mathrm{R}$ foundation for statistical computing. https://www.R-project.org/. Accessed 20 Dec 2018

Revelle W (2018) psych: procedures for personality and psychological research, Northwestern University, Evanston, Illinois, USA (R package version 1.8.10). https://CRAN.R-project.org/packa ge $=$ psych. Accessed 31 Oct 2018

Roy R, Schmitt AJ, Thomas JB, Carter CJ (2017) Review: nectar biology: from molecules to ecosystems. Plant Sci 262:148-164. https ://doi.org/10.1016/j.plantsci.2017.04.012

Sexton R (2014) The moth pollinators of greater butterfly orchids Platanthera chlorantha in Central Scotland. J Hardy Orchid Soc 11:14-22

Singaravelan N, Nee'man G, Inbar M, Izhaki I (2005) Feeding responses of free-flying honeybees to secondary compounds mimicking floral nectars. J Chem Ecol 31:2791-2804. https:// doi.org/10.1007/s10886-005-8394-z

Steen R (2012) Pollination of Platanthera chlorantha (Orchidaceae): new video registration of a hawkmoth (Sphingidae). Nord J Bot 30:623-626. https://doi.org/10.1111/j.1756-1051.2012.01574.x

Steen R, Mundal D (2013) New video registration of Autographa pulchrina (Haworth, 1809) (Lepidoptera, Noctuidae) and Sphinx pinastri L., 1758 (Lepidoptera, Sphingidae) pollinating Platanthera bifolia latiflora (Orchidaceae) in Norway. Nor J Entomol 60:57-61

Stevenson PC, Nicolson SW, Wright GA (2017) Plant secondary metabolites in nectar: impacts on pollinators and ecological functions. Funct Ecol 31:65-75. https://doi.org/10.1111/1365-2435.12761

Stpiczyńska M (2001) Nectar production characteristics and nectar chemistry of Platanthera chlorantha (Custer) Rchb. (Orchidaceae). Acta Hortic 561:137-140. https://doi.org/10.17660/ ActaHortic.2001.561.20

Stpiczyńska M (2003a) Floral longevity and nectar secretion of Platanthera chlorantha (Custer) Rchb. (Orchidaceae). Ann Bot 92:191-197. https://doi.org/10.1093/aob/mcg124

Stpiczyńska M (2003b) Nectar resorption in the spur of Platanthera chlorantha Custer (Rchb.) Orchidaceae-structural and microautoradiographic study. Plant Syst Evol 238:119-126. https://doi. org/10.1007/s00606-002-0281-2

Stpiczyńska M, Pielecki J (2002) Sekrecja, resorbcja i skład chemiczny nektaru podkolana zielonawego Plantanthera chlorantha (Custer) Rchb. (Orchidaceae) (Secretion, resorption and nectar chemistry of Greater Butterfly Orchid Platanthera chlorantha (Custer) Rchb. (Orchidaceae)). Annales UMCS Sectio EEE Horticultura 10:173-179

Thomson JD, Draguleasa MA, Tan MG (2015) Flowers with caffeinated nectar receive more pollination. Arthropod Plant Interact 9:1-7. https://doi.org/10.1007/s11829-014-9350-Z

Tiedge K, Lohaus G (2017) Nectar sugars and amino acids in dayand night-flowering Nicotiana species are more strongly shaped by pollinators' preferences than organic acids and inorganic 
ions. PLoS One 12:e0176865. https://doi.org/10.1371/journ al.pone. 0176865

Torres C, Galetto L (2002) Are nectar sugar composition and corolla tube length related to the diversity of insects that visit Asteraceae flowers? Plant Biol 4:360-366. https://doi. org/10.1055/s-2002-32326

Tremblay RL, Ackerman JD, Zimmerman JK, Calvo RN (2005) Variation in sexual reproduction in orchids and its evolutionary consequences: a spasmodic journey to diversification. Biol J Linn Soc 84:1-54. https://doi.org/10.1111/j.1095-8312.2004.00400.x

Vallius E, Salonen V (2006) Allocation to reproduction following experimental defoliation in Platanthera bifolia (Orchidaceae). Plant Ecol 183:291-304. https://doi.org/10.1007/s1125 8-005-9040-0

Vranová V, Rejšek K, Skene K, Formánek P (2010) Non-protein amino acids: plant, soil and ecosystem interactions. Plant Soil 342:3148. https://doi.org/10.1007/s11104-010-0673-y

Wei T, Simko V (2017) R package "corrplot": Visualization of a correlation matrix (version 0.84). https://cran.r-project.org/web/packa ges/corrplot/. Accessed 17 Oct 2017
Wei X, Johnson SJ, Hammond AM (1998) Sugar-feeding strategy of adult velvetbean caterpillar (Lepidoptera: Noctuidae). Environ Entomol 27:1235-1241. https://doi.org/10.1093/ee/27.5.1235

Willmer P (2011) Pollination by butterflies and moths. In: Willmer P (ed) Pollination and floral ecology. Princeton University Press, Princeton, pp 322-336. https://doi.org/10.1515/9781400838 943.322

Witt T, Jurgens A, Gottsberger G (2013) Nectar sugar composition of European Caryophylloideae (Caryophyllaceae) in relation to flower length, pollination biology and phylogeny. J Evol Biol 26:2244-2259. https://doi.org/10.1111/jeb.12224

Zhang T-F, Duan Y-W, Liu J-Q (2006) Pollination ecology of Aconitum gymnandrum (Ranunculaceae) at two sites with different altitudes. Acta Phytotaxon Sin 44:362-370. https://doi.org/10.1360/ aps050146

Publisher's Note Springer Nature remains neutral with regard to jurisdictional claims in published maps and institutional affiliations. 